\title{
Behavior in Group Contests: A Review of Experimental Research
}

\author{
Roman M. Sheremeta ${ }^{a, b, *}$ \\ ${ }^{a}$ Weatherhead School of Management, Case Western Reserve University \\ 11119 Bellflower Road, Cleveland, OH 44106, USA \\ ${ }^{\mathrm{b}}$ Economic Science Institute, Chapman University \\ One University Drive, Orange, CA 92866, USA
}

October 21, 2015

\begin{abstract}
Group contests are ubiquitous. Some examples include warfare between countries, competition between political parties, team-incentives within firms, group sports, and rent-seeking. In order to succeed, members of the same group have incentives to cooperate with each other by expending individual efforts. However, since effort is costly, each member also has an incentive to abstain from expending any effort and instead free-ride on the efforts of other members. Contest theory shows that the intensity of competition between groups and the amount of freeriding within groups depend on the group size, sharing rule, group impact function, contest success function, and heterogeneity of players. We review experimental studies testing these theoretical predictions. Almost all studies of behavior in group contests find significant overexpenditure of effort relative to the theory. We discuss potential explanations for such overexpenditure, including the utility of winning, bounded rationality, relative payoff maximization, parochial altruism, and social identity. Despite over-expenditure, most studies find support for the comparative statics predictions of the theory (with the exception of the "group size paradox"). Finally, studies show that there are effective mechanisms that can promote withingroup cooperation and conflict resolution mechanisms that can de-escalate and potentially eliminate between-group conflict.
\end{abstract}

JEL Classifications: C7, C9, D7, H4, J4, K4, L2, M5

Keywords: groups, contests, experiments

* Corresponding author: Roman Sheremeta, rms246@ case.edu and rshereme@ gmail.com I have benefitted from the helpful comments of Robert Böhm, Subhasish Chowdhury, Emmanuel Dechenaux, Cary Deck, Gerald Eisenkopf, Sergey Gavrilets, Changxia Ke, Mikael Puurtinen, Amnon Rapoport, Anya Samek and participants at the Cleveland Fed Reserve economic seminar and the Evolution and Warfare Conference at the National Institute for Mathematical and Biological Synthesis conference. I remain solely responsible for any errors or omissions. 


\section{Introduction}

Group contests are ubiquitous. Some examples include warfare between countries, competition between political parties, team-incentives within firms, group sports, and rentseeking. In order to succeed, members of the same group have incentives to cooperate with each other by expending individual efforts. However, since effort is costly, each member also has an incentive to abstain from expending any effort and instead free-ride on the efforts of other members.

A large theoretical literature shows that the intensity of competition between groups and the amount of free-riding within groups depend on many factors, including the group size, the sharing rule, and the contest success function, among others (Konrad, 2009; Kolmar, 2013; Flamand and Troumpounis, 2015; Gavrilets, 2015). Despite an extensive and established theoretical literature, much less effort has been devoted to empirically investigate individual behavior in group contests (Dechenaux et al., 2015). The main reason is that it is not trivial to measure individual effort in the field since the researcher can only observe the performance of contestants, which is a function of effort, ability and luck (Ericsson and Charness, 1994). Because it is typically difficult to measure the actual effort in group contests, many researchers use controlled laboratory experiments.

Controlled experiments allow researchers to test theoretical predictions about behavior in group contests without confounding effects mentioned above. Most experiments allow direct measurement of individual effort, while controlling for the relative abilities of contestants and the amount of luck in the contest. The purpose of this paper is to survey this work, by reviewing experimental studies of group contests conducted by the social scientists (Dechenaux et al., 2015), as well as evolutionary biologists (Gavrilets, 2015) and psychologists (Bornstein, 2003). 
We begin by providing a general theoretical model of group contests in Section 2. The model identifies five main factors influencing behavior in group contests: (1) group size, (2) sharing rule, (3) group impact function, (4) contest success function, and (5) heterogeneity of players.

In Section 3, we discuss general findings regarding behavior in group contests. The main observation, emerging from almost all experimental studies of group contests, is that the actual effort of subjects is significantly higher than the Nash equilibrium prediction. There are three types of explanations that have been offered. First, it is well documented that people behave overly competitive even in simple contests between individuals (Sheremeta, 2013, 2015). Such overly competitive behavior between individuals (which could be driven by a non-monetary utility of winning, bounded rationality, and relative payoff maximization) could intensify competition between groups, leading to over-expenditure of effort in group contests. Second, it is well-documented in social dilemmas and collective action games that individuals behave overly cooperative (Ledyard et al, 1995; Chaudhuri, 2011). Such overly cooperative behavior within groups (which could be driven by altruism, fairness, and inequality aversion) could enhance within-group cooperation in group contests, again leading to over-expenditure of effort. Finally, the third explanation takes its roots in parochial altruism (Bernhard et al., 2006; Choi and Bowles, 2007) and group identity (Tajfel and Turner, 1979), suggesting that individuals simultaneously display altruism towards in-group members along with hostility towards outgroup individuals.

In Section 4, we discuss experimental studies examining how different factors, derived from the theoretical model in Section 2, impact the observed behavior in experiments. Overall, it appears that most studies find support for the main comparative statics predictions of the theory. For example, as predicted by the theory, most experimental studies find that individual efforts 
are higher when members of the group are rewarded proportionally to their performance, or when the contest success function is more discriminatory (i.e., all-pay auction versus lottery). Also, consistent with the theoretical predictions, behavior of individuals crucially depends on the group impact function (i.e., a function specifying how individual efforts impact group performance), with the perfect-substitutes function generating the highest group effort, the weakest-link function generating the least free-riding, and the best-shot function generating the highest relative effort by strong players. Another prediction supported by the data is that when players are heterogeneous, stronger players expend more effort and weaker players are more likely to free-ride. The only comparative statics predictions of the theory which is not supported by the data is the "group size paradox" (Olson, 1965). All existing experimental studies examining the impact of group size on behavior in group contests find that larger groups are more likely to win a group contest than smaller groups, even when theory predicts otherwise.

Section 5 provides an overview of mechanisms that have been shown to be effective in promoting within-group cooperation in group contests. Some mechanisms for promoting cooperation include punishment of free-riders, within-group communication, leadership, and consistent feedback about relative group performance. Also, in Section 5 we briefly discuss some conflict resolution mechanisms that can be used to de-escalate and potentially eliminate betweengroup conflict.

Finally, Section 6 concludes by suggesting directions for future research.

\section{The Model of a Contest between Groups}

Assume there are two groups competing to win a contest and receive a prize $v$. Group $A$ consists of $N_{A}$ risk-neutral players and group $B$ consists of $N_{B}$ players. All players in both groups 
simultaneously and independently expend irreversible costly efforts $x_{i A}$ and $x_{j B}$, incurring potentially heterogeneous costs $c_{i A}\left(x_{i A}\right)$ and $c_{j B}\left(x_{j B}\right)$, for all $i=1, \ldots, N_{A}$ and $j=1, \ldots, N_{B}$.

The group performance $X_{A}$ (similarly $\left.X_{B}\right)$ is a function of all individual efforts within group $A$ :

$$
X_{A}=f_{A}\left(x_{1 A}, \ldots, x_{N_{A} A}\right)
$$

The performance function (1) is often called the group impact function (Wärneryd, 2001). The most common group impact function in the literature is the perfect-substitutes function: $f_{A}\left(x_{1 A}, \ldots, x_{N_{A} A}\right)=\sum_{i=1}^{N_{A}} x_{i A}$ (Katz et al., 1990). Contests characterized by this function resemble many real life competitions where the performance of the group depends on the joint effort of all members within that group. When the group performance depends only on the best performer within a group, such contests could be characterized by the best-shot function: $f_{A}\left(x_{1 A}, \ldots, x_{N_{A} A}\right)=\max \left\{x_{1 A}, \ldots, x_{N_{A} A}\right\}$ (Chowdhury et al., 2013). Finally, when the performance of the entire group depends on the worst performer within a group, such contests can be characterize by the weakest-link function: $f_{A}\left(x_{1 A}, \ldots, x_{N_{A} A}\right)=\min \left\{x_{1 A}, \ldots, x_{N_{A} A}\right\}$ (Lee, 2012). ${ }^{1}$

The performance of each group determines the probability of winning the contest. After all players of group $A$ and group $B$ choose their efforts, $X_{A}$ and $X_{B}$ are compared. The probability of group $A$ winning the prize is defined by a contest success function (CSF) which was first used by Tullock (1980) to describe rent-seeking contests:

$$
p_{A}\left(X_{A}, X_{B}\right)=\left(X_{A}\right)^{r} /\left(\left(X_{A}\right)^{r}+\left(X_{B}\right)^{r}\right) \text {. }
$$

If $X_{A}=X_{B}=0$ then $p_{A}\left(X_{A}, X_{B}\right)=1 / 2$. That is, each group's probability of winning depends on its relative performance. Note that $r \geq 0$ is a discrimination parameter that measures the sensitivity of the probability of winning to the ratio of group performances. The two commonly

\footnotetext{
${ }^{1}$ See Kolmar and Rommeswinkel (2013) for a generalized group impact function.
} 
used CSFs are the lottery case $(r=1)$ and the auction case $(r=\infty)$. In the lottery case, the group with higher performance has a higher chance of winning the contest, while in the all-pay auction case, the group with the highest performance wins the contest with certainty.

In the case group $A$ wins the prize, player $i$ receives a share of the prize which is defined by the following sharing rule (Nitzan, 1991):

$$
s_{i A}\left(x_{1 A}, \ldots, x_{N_{A} A}\right)=\alpha_{A} / N_{A}+\left(1-\alpha_{A}\right) x_{i A} / \sum_{i=1}^{N_{A}} x_{i A}
$$

That is, a proportion of the prize $\alpha_{A}$ is distributed equally among all group members, and the residual $1-\alpha_{A}$ is shared according to relative effort. Note that $\alpha_{A}=1$ corresponds to a completely egalitarian rule while $\alpha_{A}=0$ corresponds to a completely proportional rule.

Given (1), (2), and (3) the expected payoff of player $i$ in group $A$ can be written as:

$$
\pi_{i A}\left(x_{1 A}, \ldots, x_{N_{A} A}, X_{B}\right)=p_{A}\left(X_{A}, X_{B}\right) s_{i A} v-c_{i A}\left(x_{i A}\right)
$$

The first term of the expected payoff $p_{A}\left(X_{A}, X_{B}\right) s_{i A} v$ is the expected benefit of contributing effort $x_{i A}$. By expending a higher effort $x_{i A}$, player $i$ can increase the probability $p_{A}\left(X_{A}, X_{B}\right)$ of group $A$ winning the contest and increase the share of the prize $s_{i A} v$ in case group $A$ wins the contest. The second term is the $\operatorname{cost} c_{i A}\left(x_{i A}\right)$ of contributing effort $x_{i A}$. Therefore, player $i$ has an incentive to cooperate with other members of his group, but since cooperation is costly, there is also an incentive to free-ride. The exact equilibrium effort and the amount of free-riding crucially depend on:

1) group size $\left(N_{A}\right.$ and $\left.N_{B}\right)$

2) sharing rule $\left(\alpha_{A}\right.$ and $\left.\alpha_{B}\right)$

3) group impact function $\left(f_{A}\right.$ and $\left.f_{B}\right)$

4) contest success function (characterized by $r$ )

5) heterogeneity of players $\left(c_{i A}\right.$ and $\left.c_{j B}\right)$ 
For a more detailed review of the theoretical literature on group contests and the exact equilibrium predictions see Konrad (2009), Kolmar (2013), Flamand and Troumpounis (2015), and Gavrilets (2015). It is important to emphasize that within social sciences (e.g., economics and political science), the theoretical predictions about behavior in group contests are usually based on the assumptions of pure self-interest, full rationality, and correct beliefs about the behavior of others. ${ }^{2}$

\section{General Findings about Behavior in Group Contests}

Early experiments examining the behavior of people in group contests were conducted by psychologies Rapoport and Bornstein $(1987,1989)$ and Bornstein $(1992) .{ }^{3}$ Although subjects in these early experiments were only allowed to make somewhat unrealistic binary all-or-nothing decisions of whether to cooperate or not, the findings from these studies provided the basis for a large and growing experimental literature on group contests. ${ }^{4}$

Erev et al.'s (1993) orange grove field experiment is arguably the first experiment to examine behavior of people in naturally occurring group contests. The authors assigned subjects to three treatments. In the Personal treatment, each subject was paid according to the quantity of oranges he/she picked. In the Team treatment, each subject received an equal share of the group total payoff. In the Competition treatment, subjects received a bonus if their group was more productive than the other group (this treatment corresponds to a contest between groups). The main finding of interest is that subjects produced 35\% higher output when they participated in

\footnotetext{
${ }^{2}$ Although evolutionary biology models do not assume pure self-interest, see Gavrilets (2015).

${ }^{3}$ One could probably cite Sherif et al. (1961) as the earliest psychology experiment of the intergroup conflict.

${ }^{4}$ Experiments using binary all-or-nothing decisions have been also used in political science, since electoral competition can be modeled as a group contest in which each group members makes a choice of whether to cast a vote (cooperate) or not. For an excellent review of political science experiments see Morton and Williams (2010). Here we will discuss only some of these studies.
} 
the between-group contest. Furthermore, output tended to increase over time in the contest treatment, while it tended to fall in the other treatments. Similar qualitative results were obtained in a real-effort laboratory experiment by van Dijk et al. (2001). Together, these findings suggest that when people engage in real-effort group contests, they expend high effort and they do not free-ride.

A related study by economists Nalbantian and Schotter (1997) examined behavior in group contests, in which instead of expending real effort, subjects chose how much money to contribute to their group (higher amount of money corresponds to a higher effort level). In their experiment, there were two identical groups, consisting of six players each $\left(N_{A}=N_{B}=6\right)$, and the group performance was the sum of all the individual group members' efforts $\left(f_{A}=\sum_{i=1}^{6} x_{i A}\right.$ and $\left.f_{B}=\sum_{i=1}^{6} x_{i B}\right)$. The best performing group received the prize with certainty $(r=\infty)$ and all players of the winning group had to split the prize equally $\left(\alpha_{A}=\alpha_{B}=0\right)$. Similar to the realeffort studies of Erev et al. (1993) and van Dijk et al. (2001), Nalbantian and Schotter (1997) found that contests between groups generate very high individual efforts and relatively small amounts of free-riding.

\subsection{Over-Expenditure of Effort Relative to the Theoretical Predictions}

More recent experimental studies of group contests have contrasted the behavior of subjects relative to the theoretical predictions. For example, Abbink et al. (2010) and Ahn et al. (2011) examine behavior in lottery contests $(r=1)$ between symmetric groups $\left(N_{A}=N_{B}=4\right)$ and homogeneous players $\left(c_{i A}(x)=c_{j B}(x)=x\right)$, where the performance of a group is determined as the sum of all individual efforts within a group $\left(f_{A}(\cdot)=\sum_{i=1}^{4} x_{i A}\right.$ and $f_{B}()=$. $\left.\sum_{i=1}^{4} x_{i B}\right)$ and members of the winning group equally $\left(\alpha_{A}=\alpha_{B}=0\right)$ split the prize $v$. The 
theoretical prediction is that the sum of all efforts within a group should be equal to $v / 4$, and potentially all but one player in the group could free-ride (Baik, 1993). Both studies, however, document significant over-expenditure of effort relative to the Nash equilibrium prediction (up to five times the Nash equilibrium level) and very little free-riding. These results have been replicated by many other studies, including Sheremeta (2011), Cason et al. (2012, 2015), Leibbrandt and Sääksvuori (2012), Ke (2013), Ke et al. (2013, 2015), Eisenkopf (2014), Bhattacharya (2015), Brookins et al. (2015), and Chowdhury et al. (2015). ${ }^{5}$

These findings point out that the theory based on the assumptions of self-interest, full rationality, and correct beliefs, is not capturing some of the essential elements of human behavior. It is also possible that there are important factors which are not incorporated into the theoretical model described in Section 2.

\subsection{Explaining Over-Expenditure of Effort}

There are three types of explanations for the over-expenditure of effort in group contests.

The first explanation comes from the observation that people behave overly competitive even in simple contests between individuals. Based on a sample of 30 contest experiments between individual subjects examined by Sheremeta (2013), the median over-expenditure is $72 \% .^{6}$ Sheremeta (2010) showed that this over-expenditure is driven in part by a non-monetary utility of winning, which could be the missing factor from the theoretical model described in Section 2. Other explanations for over-expenditure in contests between individuals are bounded rationality (Fallucchi et al., 2013; Chowdhury et al., 2014; Lim et al., 2014) and relative payoff

\footnotetext{
${ }^{5}$ Effort expenditure further increases when subjects can endogenously self-select into groups (Herbst et al., 2015), when groups are penalized for expending the lowest effort (Puurtinen and Mappes, 2009; Egas et al., 2013), or when groups are rewarded for expending the highest effort (Reuben and Tyran, 2010; Markussen et al., 2014).

${ }^{6}$ The magnitude of over-expenditure in some studies is so high that on average participants receive negative payoffs (Sheremeta and Zhang, 2010; Price and Sheremeta, 2011, 2015; Chowdhury et al., 2014; Mago et al., 2015).
} 
maximization (Cason et al., 2013; Mago et al., 2015), questioning the assumptions of full rationality and self-interest on which the theoretical model is built. ${ }^{7}$ Irrespective of the exact reason, the fact that people display overly competitive behavior in contests between individuals could explain over-expenditure of effort in contests between groups. ${ }^{8}$

The second explanation is based on the observation that people behave overly cooperative when participating in social dilemmas and collective action games. For example, when participating in public goods games, subjects often contribute more to the group account than predicted by the rational self-interest game theoretic model (Ledyard et al, 1995; Chaudhuri, 2011). Potential explanations for such behavior include altruism (Andreoni, 1989, 1990), fairness concerns (Rabin, 1993), and inequality aversion (Fehr and Schmidt, 1999). These same explanations can be applied to explain high levels of within-group cooperation, and thus overexpenditure of effort, in contests between groups. It is important to emphasize, however, that the assumption here is that when put into a group contest, people restrict their cooperative behavior only to their own group.

The third explanation, combining the elements of the second and the third explanations, is based on the argument that individuals often display altruism towards in-group members along with hostility towards out-group individuals. Such behavior is often attributed to parochial altruism (Bernhard et al., 2006; Choi and Bowles, 2007) and social identity (Tajfel and Turner, 1979; Sen, 2007). Parochial altruism is a concept which evolutionary biologists use to explain non-kin altruism (Rusch, 2014). The main idea is that cooperativeness towards the in-group

\footnotetext{
${ }^{7}$ For the details on how to incorporate the non-monetary utility of winning, bounded rationality, and relative payoff maximization into a standard theoretical contest model see Sheremeta $(2013,2015)$.

${ }^{8}$ It is important to emphasize, however, that overly competitive behavior of individuals is unlikely to explain the full extent of over-expenditure of effort in group contests. This is mainly because the extent of over-expenditure in contests between groups is much larger than the extent of over-expenditure in contests between individuals (Abbink et al., 2010). This phenomenon is known as an "interindividual-intergroup discontinuity" (Wildschut et al., 2003; Wildschut and Insko, 2007; Abbink et al., 2010).
} 
members and aggressiveness against the out-group individuals could have coevolved in humans as means of survival. However, although most studies find evidence of altruism towards in-group members, hostile behavior towards out-group individuals is not as common (Halevy et al., 2008; Israel et al., 2012). ${ }^{9}$ Moreover, in a comprehensive review of the literature, Yamagishi and Mifune (2016) argue that evidence for parochial altruism is mixed. Another explanation of high within-group cooperation and between-group competition comes from social identity theory (Cason et al., 2012; Chowdhury et al., 2015). According to social identity theory (Tajfel and Turner, 1979; Sen, 2007), a salient group identity can cause a blurring of the boundaries between personal and group welfare and produce behavior that is contrary to personal self-interest and is instead in the interest of group benefit.

Parochial altruism and group identity are good candidates at explaining over-expenditure of effort in group contests, although it is also possible that such over-expenditure can be explained by the utility of winning, bounded rationality, and relative payoff maximization. ${ }^{10}$ More research is needed to further differentiate these competing explanations.

\section{Factors Influencing Behavior in Group Contests}

The theoretical model presented in Section 2 identifies the main factors influencing behavior in group contests, such as (1) group size, (2) sharing rule, (3) group impact function, (4) contest success function, and (5) heterogeneity of players. In this section, we discuss

\footnotetext{
${ }^{9}$ Several studies suggest that it is mostly subjects with pro-social preferences that engage in parochial altruistic behavior (Aaldering et al., 2013; Böhm et al., 2014), thus leading to a somewhat paradoxical conclusion that prosocial behavior leads to a between-group conflict. De Dreu et al. (2015) show such pro-social behavior is relative automatic and fast (and it decreases as cognitive load increases). Böhm et al. (2015) find causal evidence that the intention to protect the in-group is a significant motive of out-group hostility. Such intentions may promote preemptive offensive actions against out-group threat. De Dreu et al. (2010) provide evidence that oxytocin promotes in-group cooperation, and defensive, but not offensive, aggression toward competing out-groups.

${ }^{10}$ It is also possible that these factors are interdependent. For example, group identity could change social preferences (e.g., Chen and Li, 2009) and increase the utility of relative payoff maximization (Böhm et al., 2013).
} 
experimental studies examining how these factors impacts actual behavior of subjects in controlled experiments.

\subsection{Group Size}

Since Olson (1965), a number of theoretical and experimental papers have tried to address the question of how group size impacts individual and group behavior. A well-known "group size paradox" suggests that in the context of a between-group contest, the smaller group may be more effective and more likely to win a group contest because the larger group faces bigger free-riding problem. This paradox has been proven theoretically in some contexts (e.g., Katz and Tokatlidu, 1996; Baik and Lee, 1997), but not in others (e.g., Sandler, 1993; Esteban and Ray, 2001).

The first experimental investigation of how group size impacts individual behavior in group contests dates to Rapoport and Bornstein (1989). In their experiment, a small group of 3 individuals $\left(N_{A}=3\right)$ competes against a large group of 5 individuals $\left(N_{B}=5\right)$. Individuals within each group have to make a binary all-or-nothing decision whether to cooperate or not. The results of the experiment show that subjects in the larger group expend less effort than subjects in the smaller group. However, despite higher incentives to free-ride, the larger group is more likely to win than the smaller group. ${ }^{11}$ Similarly, in the context of political competition, Levine and Palfrey (2007) find evidence that effort decreases as group size increases, and there is less freeriding in smaller groups. Nevertheless, at the aggregate level, larger groups are still more likely to win than smaller groups.

Kugler et al. (2010) extend the earlier study of Rapoport and Bornstein (1989) to the case of a continuous effort (instead of a binary all-or-nothing decision). In their experiment, a small

\footnotetext{
11 The findings of Rapoport and Bornstein (1989) have been replicated by Zhang (2012).
} 
group of 3 individuals $\left(N_{A}=3\right)$ competes against a large group of 5 individuals $\left(N_{B}=5\right)$ for a prize of 150 . The equilibrium prediction is that under the egalitarian sharing rule $\left(\alpha_{A}=1\right)$, members of the three-person group are predicted to contribute effort of 7.8 and members of the five-person group are predicted to contribute 2.8, while under the proportional rule $\left(\alpha_{A}=0\right)$, members of both groups are predicted to contribute 32.8. Therefore, theory predicts that the "group size paradox" should emerge under the egalitarian rule but not under the proportional rule. The results of the experiment, however, show that under both rules the larger group is more likely to win the group contest.

Abbink et al. (2010) and Ahn et al. (2011) also employ several treatments which allow them to examine the effect of group size on behavior. Both studies compare a treatment in which 1 individual competes against a group of 4 individuals $\left(N_{A}=1\right.$ versus $\left.N_{B}=4\right)$ with a treatment in which a group of 4 individuals competes against a group of 4 individuals $\left(N_{A}=4\right.$ versus $N_{B}=4$ ). They find that, contrary to the theoretical prediction of Katz et al. (1990), group effort increases in the size of the group, making it unlikely for the small group to win the contest against the large group. ${ }^{12} \mathrm{Ke}$ (2013) employs a similar design and also finds that that the larger group $\left(N_{A}=2\right)$ expends higher effort than an individual $\left(N_{A}=1\right)$. Therefore, it appears that all three studies find that larger groups are more likely to win a group contest than smaller groups.

To summarize, all existing experimental studies examining the impact of group size on behavior in group contests find that larger groups are more likely to win a group contest than smaller groups, even when the theory predicts otherwise.

\footnotetext{
${ }^{12}$ Cherry and Cotten (2011) extend the theoretical analysis of Katz et al. (1990) by introducing the possibility that the two competing groups may be interdependent (i.e., individuals can be part of both sides of a contest). Theoretical and experimental results indicate that individual efforts by group members decrease and individual efforts of those outside the group increase in the relative size of the group.
} 


\subsection{Sharing Rule}

Most experimental studies examine group contests in which the prize is shared equally $\left(\alpha_{A}=1\right)$ between all individuals within the winning group (e.g., Nalbantian and Schotter, 1997; Abbink et al., 2010, 2012; Ahn et al., 2011; Sheremeta, 2011; Cason et al., 2012, 2015; Chowdhury et al., 2015). Such an egalitarian sharing rule creates incentives for some group members to free-ride on the effort of others. One possible solution is a proportional sharing rule $\left(\alpha_{A}=0\right)$, where players of the winning group split the prize in proportion to the efforts that they contributed to the group performance. There are several experimental studies (e.g., Ke et al., 2013, 2015) employing both proportional sharing and equal sharing rules in the context of alliance formation. However, due to a two-stage nature of these studies, they do not allow for a direct comparison of how the sharing rule impacts individual and group behavior.

There are three studies directly comparing the egalitarian rule $\left(\alpha_{A}=1\right)$ to the proportional rule $\left(\alpha_{A}=0\right)$, which are done by Amaldoss et al. (2000), Gunnthorsdottir and Rapoport (2006) and Kugler et al. (2010). The main finding from these studies is that, as predicted by the theory, the proportional sharing rule elicits higher individual efforts than the egalitarian rule. In a slightly different environment, Sutter (2006) studies group performance when the prize is either split equally or determined endogenously through a bargaining process between group members. Consistent with theoretical predictions, the results of the experiment indicate that subjects expend higher efforts under the bargaining scheme than under the egalitarian sharing rule.

Together, the findings from the experiments on the group sharing rule strongly confirm theoretical predictions that individual efforts are higher when members of the group are rewarded proportionally to their performance. 


\subsection{Group Impact Function}

The most commonly employed group impact function in experimental studies of group contests is the perfect-substitutes (or additive) function $\left(f_{A}\left(x_{1 A}, \ldots, x_{N_{A} A}\right)=\sum_{i=1}^{N_{A}} x_{i A}\right)$, so that the group performance depends on the joint effort of all members within that group (e.g., Abbink et al., 2010, 2012; Ahn et al., 2011; Leibbrandt and Sääksvuori, 2012; Ke et al., 2013, 2015). Recall, that the common finding of these studies is that there is significant over-expenditure of effort relative to the Nash equilibrium prediction. Nevertheless, some free-riding still exists in group contests employing perfect-substitutes function (Sheremeta, 2011).

When the performance of the entire group depends on the worst performer within the group $\left(f_{A}\left(x_{1 A}, \ldots, x_{N_{A} A}\right)=\min \left\{x_{1 A}, \ldots, x_{N_{A} A}\right\}\right)$, the group impact function is the weakest-link function. Sheremeta (2011) examines behavior in group contests with the weakest-link group impact function and finds that members of the same group learn how to coordinate on a joint group effort and free-riding is almost nonexistent. These results are replicated by Cason et al. $(2012,2015)$, who further document that in the weakest-link contests most groups reach a very high level of cooperation when they are allowed to communicate.

Finally, when the performance of a group depends only on the best performer within the group $\left(f_{A}\left(x_{1 A}, \ldots, x_{N_{A} A}\right)=\max \left\{x_{1 A}, \ldots, x_{N_{A} A}\right\}\right)$, the group performance function is the best-shot function. The only study examining behavior in group contests with the best-shot group impact function is done by Sheremeta (2011). Not surprisingly, the results show that in best-shot group contests, most of the effort is expended by strong players while weak players free-ride.

When comparing behavior in different group contests, Sheremeta (2011) concludes that effort crucially depends on the group impact function, with the perfect-substitutes function 
generating the highest group effort, the weakest-link function generating the least free-riding, and the best-shot function generating the highest relative effort by strong players. ${ }^{13}$ It is important to emphasize, however, that all papers discussed in this sub-section, including Sheremeta (2011), employ a completely egalitarian rule of sharing the prize (i.e., $\alpha_{A}=1$ ) and a linear cost of effort (i.e., $c_{i A}(x)=c_{i A} x$ ). One may expect that the results could change when using a proportional sharing rule or a convex cost of effort, which is an interesting question for future experimental research.

\subsection{Contest Success Function}

As we have previously discussed, the two most commonly used contest success functions to model behavior in group contests are the lottery CSF $(r=1)$ and the auction CSF $(r=\infty)$. Experimental studies of group contests, however, have mostly employed the lottery CSF (e.g., Gunnthorsdottir and Rapoport, 2006; Abbink et al., 2010, 2012; Kugler et al., 2010; Ahn et al., 2011; Sheremeta, 2011; Cason et al., 2012, 2015; Ke et al., 2013, 2015). The main reason is that group contests employing the lottery CSF usually have pure strategy equilibria, making it easier for subjects to learn and for researchers to analyze the data, while contests employing the auction CSF have only non-degenerate mixed strategy equilibria (Konrad, 2009). Nevertheless, some studies on group contests have employed the auction CSF (Rapoport and Bornstein, 1987, 1989; Bornstein, 1992; Levine and Palfrey, 2007; Kugler and Bornstein, 2013). One common finding is that under both CSFs there is significant over-expenditure of effort. Unfortunately, a direct comparison between group contest studies employing different CSFs is difficult because studies

\footnotetext{
${ }^{13}$ An interesting extension which has not been examined in the laboratory is the question of contests between asymmetric groups, where asymmetry comes from the fact that the performance of one group is characterized, for example, by the best-shot group impact function while the performance of the other group is characterized by the weakest-link group impact function (Chowdhury and Topolyan, 2015).
} 
that use different CSFs also use quite different experimental designs (i.e., binary all-or-nothing versus continuous strategy space).

One place where we could get some idea of how CSF impacts behavior in group contests is contests between individual players. One of the first experimental contest studies by Millner and Pratt (1989) examined behavior of subjects in a two-player contest (e.g., $N_{A}=1$ versus $\left.N_{B}=1\right)$ under the lottery CSF $(r=1)$ and the auction-like CSF $(r=3)$. The experiment showed that subjects expend higher efforts when $r=3$ than when $r=1$. The follow-up studies by Potters et al. (1998) and Davis and Reilly (1998) have directly compared behavior under the lottery CSF ad under the auction CSF, with both studies finding that subjects expend higher efforts when $r=\infty$ than when $r=1$.

In summary, experimental studies of contests between individuals find that, consistent with the theoretical predictions, the auction CSF leads to a higher effort and more competitive behavior than the lottery CSF. However, it is important to exercise caution when extrapolating these findings to group contests. Future studies should directly examine how CSF impacts behavior in group contests.

\subsection{Heterogeneity of Players}

Most studies on contests between groups assume that players within each group have identical valuation for the prize. One exception is Sheremeta (2011), who investigates lottery contests between groups, where each group has one stronger player, with a higher valuation for the prize, and two weaker players, with lower valuations. The experiment employs a perfectsubstitutes, a best-shot, and a weakest-link group impact functions. The results show that stronger players expend more effort and weaker players are more likely to free-ride in perfect- 
substitutes and best-shot contests. As a result, sometimes stronger players earn lower payoffs than weaker players. On the other hand, there is almost no free-riding and both stronger and weaker players expend similar effort in weakest-link contests.

Brookins et al. (2015) examines behavior of heterogeneous agents in the context of sorting into groups. Consistent with the theoretical predictions of Ryvkin (2011), they find that subjects in perfect-substitutes contests expend higher aggregate effort when heterogeneity between groups is lower. Also, similar to the findings of Sheremeta (2011), stronger players expend more effort (and sometimes earn lower payoff) than weaker players.

There are several studies investigating how heterogeneity of groups impacts behavior in between-group contests. Bhattacharya (2015) examines contests in which one group has a greater probability of winning (unfair contests) or has a lower cost of exerting effort (uneven contests), creating heterogeneity of players in different groups. Similarly, Hargreaves-Heap et al. (2015) examines contests between groups with unequal resources. Both studies employ a completely egalitarian rule of sharing the prize (i.e., $\alpha_{A}=1$ ), and they find that stronger players (e.g., players from stronger groups) exert higher effort than weaker players and the results are mostly consistent with the comparative statics predictions of the theory.

Finally, in the context of political competition, Levine and Palfrey (2007) design an experiment to test the comparative statics predictions of the group contest model by Palfrey and Rosenthal (1985). They find evidence for the size effect, the competition effect, and the underdog effect. Relevant to our discussion, they also find that stronger players (who have lower voting cost) expend higher effort than weaker players.

Overall, it seems that all experimental studies examining behavior of heterogeneous players in group contests find that, consistent with the theoretical predictions, stronger players 
expend more effort and weaker players are more likely to free-ride. As a result, sometimes stronger players earn lower payoffs than weaker players. It is important to emphasize, however, that these conclusions are drawn from the studies employing a completely egalitarian rule (i.e., $\alpha_{A}=1$ ). More research is needed to show the robustness of these findings.

\section{Mechanisms Promoting Cooperation}

In this section we review mechanisms that have been shown to be effective in promoting within-group cooperation in group contests. Also, we briefly discuss some conflict resolution mechanisms that can be used to de-escalate and potentially eliminate between-group conflict. In is important to emphasize, however, that within the context of contests between groups, increase of within-group cooperation automatically leads to increase of between-group competition. Therefore, in most cases, it is impossible to satisfy both of these objectives simultaneously.

\subsection{Within-Group Cooperation}

Previously we have discussed that conflicts between groups generate high within-group cooperation. Indeed a number of studies have shown that between-group competition can be used to resolve the problem of uncooperative behavior within groups (Puurtinen and Mappes, 2009; Reuben and Tyran, 2010; Burton-Chellew and West, 2012; Cabrera et al., 2013) and coordination failure in teams (Bornstein et al., 2002; Cason et al., 2012). Moreover, given a choice, individuals often endogenously choose to employ competition between groups in order to promote within-group cooperation (Markussen et al., 2014; Puurtinen et al., 2015). However, 
besides the direct effect of between-group competition on within-group cooperation, there are behavioral mechanisms that can be used to increase within-group cooperation. ${ }^{14}$

Abbink et al. (2010) find that within-group cooperation is enhanced when group members are allowed to punish free-riders. However, such enhanced within-group cooperation comes at the cost of higher between-group competition (up to nine times higher than the Nash equilibrium). Therefore, while it is clear that the introduction of within-group punishment promotes within-group cooperation, it is not clear whether such punishment is necessarily beneficial to the group. Sääksvuori et al. (2011), however, show that groups that have access to within-group punishment outperform groups that do not have such access, thus concluding that costly punishment entails significant individual benefits in a population of competing groups.

A number of studies show that the introduction of within-group communication can enhance cooperation and coordination within a group (Bornstein, 1992; Bornstein et al., 2002; Sutter and Strassmair, 2009; Cason et al., 2012, 2015; Leibbrandt and Sääksvuori, 2012). However, similar to Abbink et al. (2010), Cason et al. (2012) point out that enhanced cooperation and coordination within each competing group may lead to extensive and inefficient competition between groups. They conclude that communication should not be interpreted generally as an efficiency-enhancing mechanism. Cason et al. (2015) further explore the potentially harmful effects of within-group communication, and find that despite "harmful"

\footnotetext{
${ }^{14}$ Here we discuss mechanisms of within-group cooperation only in the context of contests between groups. There is, however, a large literature examining mechanisms of cooperation in social dilemmas and collective action games (Kollock, 1998; Chaudhuri, 2011). Some mechanisms that have been suggested by this literature include communication (Isaac and Walker, 1988; Bochet et al., 2006), punishment of free-riders (Fehr and Gächter, 2002), recognition of the top performers (Samek and Sheremeta, 2014; 2015), reputation and feedback (Kurzban and DeScioli, 2008; McCarter and Sheremeta, 2013), and behavioral spillovers (Cason et al., 2012; Savikhin and Sheremeta, 2013; McCarter et al., 2014).
} 
effects of communication, groups endogenously and consistently choose to communicate even though this leads to lower payoffs and efficiency. ${ }^{15}$

Eisenkopf (2014) examines the role of leadership on within-group coordination. In different experimental treatments the leader either benefits from high or low group effort or gets a predetermined payment. The results show that group leaders can coordinate the competitive behavior of their group members. Leaders who benefit from high (low) effort of their group members induce the highest (the lowest) effort from group members. In general, group members in all treatments adjust their behavior according to the recommendation of the group leader, especially if leaders get a fixed rather than an outcome-dependent payment.

Finally, Tan and Bolle (2007) suggest a simple mechanism for promoting within-group cooperation without detrimental effects of between-group conflict. Instead of directly assigning subjects to the between-group conflict, they create an environment in which each group competes to be ranked higher than the other group. Even though groups do not compete directly, the experiment shows that such "virtual competition" promotes within-group cooperation. Several follow-up studies have shown that even by simply providing feedback about the relative performance of each group (which are not in direct competition with each other), one can increase within-group cooperation (Böhm and Rockenbach, 2013; Cárdenas and Mantilla, 2015). The advantage of these mechanisms is that the benefit of within-group cooperation is achieved without the cost of between-group competition.

\footnotetext{
${ }^{15}$ One reason for this result is that incentives are structured in such a way that choosing to communicate is a weakly dominant strategy. Communication helps groups to act as one individual player (Sutter and Strassmair, 2009; Cason et al., 2012; Zhang, 2012), and individual players (acting in the role of a group) are usually more likely to win against the competing group (Kugler and Bornstein, 2013).
} 


\subsection{Conflict Resolution and Endogenous Formation of Alliances}

Given the very high over-expenditure of effort resulting from intense competition between groups, it is imperative to examine what are the effective mechanisms of resolving conflicts between groups. There is a growing experimental literature studying conflict resolution mechanisms in the laboratory. Most of these studies focus on resolving conflicts between individuals. Some mechanism that have been shown to be effective include communication between competing parties (Tingley and Walter, 2011; Cason et al., 2012), side-payments (Kimbrough and Sheremeta 2013, 2014), the use of a coordination device (Kimbrough et al., 2014), costly commitments (Kimbrough et al., 2015), and mediation (Eisenkopf, 2015). In the context of group contests, only one of these conflict resolution mechanisms has been studied in the laboratory. Specifically, Cason et al. (2012) have shown that in the weakest-link group contest communication between groups can de-escalate and potentially eliminate between-group conflict. Similar results also exist in perfect-substitutes group contests (Bornstein, 1992; Leibbrandt and Sääksvuori, 2012). Unfortunately, other conflict resolution mechanisms have not been studied in the context of group contests. This is an open area for future research.

A natural extension to the studies examining conflict resolution between groups is the question of alliance formation (for a survey, see Bloch, 2012). Given that some groups can completely resolve their conflicts, it is natural to ask whether they would be willing to form an alliance when facing a common enemy. To examine this question, Deck et al. (2015) model a situation in which an attacker observes the defenders' decision to form an alliance and the level

of defense before acting. An important implication of their model is that if the defenders form an alliance then their expected payoffs increase despite the fact that a successful attack is more likely. Experimentally, alliances yield higher payoffs to defenders as predicted, but also reduce 
the likelihood of a successful attack, counter to the theoretical prediction. Herbst et al. (2015) also examine the endogenous formation of alliances, and find that less competitive contestants display a greater willingness to form alliances. Despite this observed self-selection of less aggressive subjects into alliances, endogenous alliances tend to generate higher effort than exogenously formed alliances. ${ }^{16}$

\section{Conclusions and Future Directions}

There are several important lessons that emerge from the papers that we surveyed. First, almost all laboratory studies of behavior in group contests find significant over-expenditure of effort relative to the Nash equilibrium prediction. Second, most experimental studies find support for the comparative statics predictions of the theory (with the exception of the "group size paradox"). Third, there are effective mechanisms that can promote within-group cooperation and conflict resolution mechanisms that can de-escalate and potentially eliminate between-group conflict (although usually it is impossible to satisfy both of these objectives simultaneously).

We see a number of fruitful avenues for future experimental research on group contests. First, the over-expenditure of effort in group contests is still an open question. As discussed in Section 3, such over-expenditure can be driven by (1) overly competitive behavior which is usually observed when individuals compete against others in contests, or (2) overly cooperative behavior which is usually observed in social dilemmas and collective action games. It is also possible that over-expenditure is driven by parochial altruism, which would imply that (1) and (2) are acting simultaneously and are positively correlated. Currently, there is no consensus on this issue (Yamagishi and Mifune, 2016), and so more research is needed.

\footnotetext{
${ }^{16}$ Other experimental studies of alliances are done by Amaldoss et al. (2000), Ke (2011), and Ke et al. (2013, 2015).
} 
Second, given that evolutionary biology suggests that individual non-kin altruism could have emerged endogenously through competition between groups (Rusch, 2014), it is imperative to examine endogenous emergence of group conflicts and whether this process stimulates individual self-selection into types (i.e., altruistic types versus competitive types). One could potentially design an experiment resembling the environment of Choi and Bowles (2007), but instead of exogenously assigning specific types, allow individual subjects endogenously form groups and choose their own types. This environment would be difficult to analyze using traditional game-theoretic tools, but it could be easily studied using experiments. ${ }^{17}$

Third, many results that we reviewed in this survey were established under quite restrictive conditions. For example, all papers examining how group impact function influences individual behavior in group contests employ a completely egalitarian rule of sharing the prize and a linear cost of effort. Similarly, all experimental studies examining behavior of heterogeneous players employ the egalitarian rule. Therefore, more research is needed to show that the results from these studies are robust when the cost of effort is convex and when the prize is shared proportionally to individual effort.

Finally, we have mentioned that some theoretical predictions about behavior in group contests have only been studied using contests between individuals. For example, the finding that a more discriminatory contest success function generates higher effort has only been documented in contests between individuals (Millner and Pratt, 1989; Davis and Reilly, 1998; Potters et al., 1998), and more research is needed to examine the robustness of these results in the context of group contests. Similarly, most conflict resolution mechanisms (such as side-payments, the use of a coordination device, costly commitments, and mediation) have been studied in the context of

\footnotetext{
${ }^{17}$ See an example of a similar type of an experiment by DeScioli and Wilson (2011).
} 
a conflict between two individuals. More research is needed to determine whether such mechanisms can be used to de-escalate and potentially eliminate between-group conflicts. 


\section{References}

Aaldering, H., Greer, L.L., Van Kleef, G.A. and De Dreu, C.K. (2013). Interest (mis) alignments in representative negotiations: Do pro-social agents fuel or reduce inter-group conflict? Organizational Behavior and Human Decision Processes, 120, 240-250.

Abbink, K., Brandts, J., Herrmann, B. \& Orzen, H. (2010). Inter-group conflict and intra-group punishment in an experimental contest game. American Economic Review, 100, 420-447.

Abbink, K., Brandts, J., Herrmann, B. \& Orzen, H. (2012). Parochial altruism in inter-group conflicts. Economics Letters, 117, 45-48.

Ahn, T.K., R, Isaac, M. \& Salmon, T.C. (2011). Rent seeking in groups. International Journal of Industrial Organization, 29, 116-125.

Amaldoss, W., Meyer, R.J., Raju, J.S. \& Rapoport, A. (2000). Collaborating to compete: A game-theoretical model and empirical investigation of the effect of profit-sharing arrangement and type of alliance. Marketing Science, 19, 105-126.

Andreoni, J. (1989). Giving with impure altruism: Applications to charity and Ricardian equivalence. Journal of Political Economy, 97, 1447-1458.

Andreoni, J. (1990). Impure altruism and donations to public goods: A theory of warm-glow giving. Economic Journal, 100, 464-477.

Baik, K.H. (1993). Effort levels in contests: The public-good prize case. Economics Letters, 41, 363-367.

Baik, K.H., \& Lee, S. (1997). Collective rent seeking with endogenous group sizes. European Journal of Political Economy, 13, 121-130.

Bernhard, H., Fischbacher, U., \& Fehr, E. (2006). Parochial altruism in humans. Nature, 442, 912-915.

Bhattacharya, P. (2015). Inter-team contests with asymmetric power differential. Working Paper.

Bloch, F. (2012). Endogenous formation of alliances in conflicts. In Michelle R. Garfinkel and Stergios Skaperdas, (Eds.), Oxford Handbook of the Economics of Peace and Conflict. Oxford University Press, New York.

Bochet, O., Page, T., \& Putterman, L. (2006). Communication and punishment in voluntary contribution experiments. Journal of Economic Behavior \& Organization, 60, 11-26.

Böhm, R., \& Rockenbach, B. (2013). The inter-group comparison-intra-group cooperation hypothesis: comparisons between groups increase efficiency in public goods provision. PloS One, 8, 1-7.

Böhm, R., Bornstein, G., \& Koppel, H. (2014). Between-group conflict and other-regarding preferences in nested social dilemmas. Working Paper.

Böhm, R., Rothermund, K., \& Kirchkamp, O. (2013). Social categorization and group-motivated interindividual-intergroup discontinuity. European Journal of Social Psychology, 43, 40-49.

Böhm, R., Rusch, H., \& Gürerk, Ö. (2015). What makes people go to war? Defensive intentions motivate retaliatory and preemptive intergroup aggression. Evolution and Human Behavior, forthcoming.

Bornstein, G. (1992). The free-rider problem in intergroup conflicts over step-level and continuous public goods. Journal of Personality and Social Psychology, 62, 597-606.

Bornstein, G. (2003). Intergroup conflict: Individual, group, and collective interests. Personality and Social Psychology Review, 7, 129-145.

Bornstein, G., Gneezy, U., \& Nagel, R. (2002). The effect of intergroup competition on intragroup coordination: An experimental study. Games and Economic Behavior, 41, 1-25. 
Brookins, P., Lightle, J. P., \& Ryvkin, D. (2015). An experimental study of sorting in group contests. Labour Economics, 35, 16-25.

Burton-Chellew, M.N., \& West, S.A. (2012). Pseudocompetition among groups increases human cooperation in a public-goods game. Animal Behaviour, 84, 947-952.

Burton-Chellew, M.N., Ross-Gillespie, A., \& West, S.A. (2010). Cooperation in humans: competition between groups and proximate emotions. Evolution and Human behavior, 31, 104-108.

Cabrera, S., Fatás, E., Lacomba, J.A., \& Neugebauer, T. (2013). Splitting leagues: promotion and demotion in contribution-based regrouping experiments. Experimental Economics, 16, 426441.

Cárdenas, J.C., \& Mantilla, C. (2015). Between-group competition, intra-group cooperation and relative performance. Frontiers in Behavioral Neuroscience, 9, 1-9.

Cason, T.N., Masters, W., \& Sheremeta, R.M. (2013). Winner-take-all and proportional-prize contests: theory and experimental results. Working Paper.

Cason, T.N., Sheremeta, R.M. \& Zhang, J. (2012). Communication and efficiency in competitive coordination games. Games and Economic Behavior, 76, 26-43.

Cason, T.N., Sheremeta, R.M. \& Zhang, J. (2015). Asymmetric and endogenous communication in competition between groups. Working Paper.

Chaudhuri, A. (2011). Sustaining cooperation in laboratory public goods experiments: a selective survey of the literature. Experimental Economics, 14, 47-83.

Chen, Y., \& Li, S.X. (2009). Group identity and social preferences. American Economic Review, 99, 431-457.

Cherry, T.L. \& Cotten, S.J. (2011). Sleeping with the enemy: The economic cost of internal environmental conflicts. Economic Inquiry, 49, 530-539.

Choi, J.K., \& Bowles, S. (2007). The co-evolution of parochial altruism and war. Science, 318, $636-640$.

Chowdhury, S.M., \& Topolyan, I. (2015). The attack-and-defense group contests: Best-shot versus weakest-link. Economic Inquiry, forthcoming.

Chowdhury, S.M., Jeon, J.Y., \& Ramalingam, A. (2015). Identity and group conflict. Working Paper.

Chowdhury, S.M., Lee, D., \& Sheremeta, R.M. (2013). Top guns may not fire: Best-shot group contests with group-specific public good prizes. Journal of Economic Behavior \& Organization, 92, 94-103.

Chowdhury, S.M., Sheremeta, R.M., \& Turocy, T. (2014). Overbidding and overspreading in rent-seeking experiments: Cost structure and prize allocation rules. Games and Economic Behavior, 87, 224-238.

Davis, D., \& Reilly, R. (1998). Do many cooks always spoil the stew? An experimental analysis of rent seeking and the role of a strategic buyer. Public Choice, 95, 89-115.

De Dreu, C.K., Dussel, D.B., \& Ten Velden, F.S. (2015). In intergroup conflict, self-sacrifice is stronger among pro-social individuals, and parochial altruism emerges especially among cognitively taxed individuals. Frontiers in Ppsychology, 6, 1-9.

De Dreu, C.K., Greer, L.L., Handgraaf, M.J., Shalvi, S., Van Kleef, G.A., Baas, M., Ten Velden, F.S., Van Dijk, E., \& Feith, S.W. (2010). The neuropeptide oxytocin regulates parochial altruism in intergroup conflict among humans. Science, 328, 1408-1411.

Dechenaux, E., Kovenock, D., \& Sheremeta, R.M. (2015). A survey of experimental research on contests, all-pay auctions and tournaments. Experimental Economics, forthcoming. 
Deck, C., Foster, J., Song, H. (2015). Alliances in defense against an opportunistic opponent: Theory and experiments. European Journal of Operational Research, forthcoming

DeScioli, P., \& Wilson, B.J. (2011). The territorial foundations of human property. Evolution and Human Behavior, 32, 297-304.

Egas, M., Kats, R., van der Sar, X., Reuben, E., \& Sabelis, M.W. (2013). Human cooperation by lethal group competition. Scientific Reports, 3, 1-4.

Eisenkopf, G. (2014). The impact of management incentives in intergroup contests. European Economic Review, 67, 42-61.

Eisenkopf, G. (2015). Communication and conflict management. Working Paper.

Erev, I., Bornstein, G., \& Galili, R. (1993). Constructive intergroup competition as a solution to the free rider problem: A field experiment. Journal of Experimental Social Psychology, 29, 463-478.

Ericsson, K.A., \& Charness, N. (1994). Expert performance: Its structure and acquisition. American Psychologist, 49, 725 - 747.

Esteban, J., \& Ray, D. (2001). Collective action and the group size paradox. American Political Science Review, 95, 663-672.

Fallucchi, F., Renner, E., \& Sefton, M. (2013). Information feedback and contest structure in rent-seeking games. European Economic Review, 64, 223-240.

Fehr, E., \& Gächter, S. (2002). Altruistic punishment in humans. Nature, 415, 137-140.

Fehr, E., \& Schmidt, K.M. (1999). A theory of fairness, competition, and cooperation. Quarterly Journal of Economics, 114, 817-868.

Flamand, S., \& Troumpounis, O. (2015). Prize-sharing rules in collective rent seeking. In Congleton, R.D., Hillman, A.L., (Eds.), Companion to political economy of rent seeking, London: Edward Elgar, pp. 92-112.

Gavrilets, S. (2015). Collective action problem in heterogeneous groups. Philosophical Transactions B, forthcoming.

Gunnthorsdottir, A., \& Rapoport, A. (2006). Embedding social dilemmas in intergroup competition reduces free-riding. Organizational Behavior and Human Decision Processes, 101, 184-199.

Halevy, N., Bornstein, G., \& Sagiv, L. (2008). "In-group love" and "out-group hate" as motives for individual participation in intergroup conflict: A new game paradigm. Psychological Science, 19, 405-411.

Hargreaves-Heap, S., Ramalingam, A., Ramalingam, S., \& Stoddard, B. (2015). 'Doggedness' or 'disengagement'? An experiment on the effect of inequality in endowment on behavior in team competitions. Journal of Economic Behavior \& Organization, forthcoming.

Herbst, L., Konrad, K.A. \& Morath, F. (2015). Endogenous group formation in experimental contests. European Economic Review, 74, 163-189.

Isaac, R., \& Walker, J. (1988). Communication and free riding behavior: the voluntary contributions mechanism. Economic Inquiry, 26, 585-608.

Israel, S., Weisel, O., Ebstein, R.P., \& Bornstein, G. (2012). Oxytocin, but not vasopressin, increases both parochial and universal altruism. Psychoneuroendocrinology, 37, 1341- 1344.

Katz, E., \& Tokatlidu, J. (1996). Group competition for rents. European Journal of Political Economy, 12, 599-607.

Katz, E., Nitzan, S., \& Rosenberg, J. (1990). Rent-seeking for pure public goods. Public Choice, 65, 49-60.

Ke, C. (2013). Fight alone or together? The need to belong. Working Paper. 
Ke, C., Konrad, K.A. \& Morath, F. (2013). Brothers in arms - An experiment on the alliance puzzle. Games and Economic Behavior, 77, 61-76.

Ke, C., Konrad, K.A., \& Morath, F. (2015). Alliances in the shadow of conflict. Economic Inquiry, 53, 854-871.

Kimbrough, E.O., \& Sheremeta, R.M. (2013). Side-payments and the costs of conflict. International Journal of Industrial Organization, 31, 278-286.

Kimbrough, E.O., \& Sheremeta, R.M. (2014). Why can't we be friends? Entitlements and the costs of conflict. Journal of Peace Research, 51, 487-500.

Kimbrough, E.O., Rubin, J., Sheremeta, R.M., \& Shields, T.W. (2015). Commitment problems in conflict resolution. Journal of Economic Behavior \& Organization, 112, 33-45.

Kimbrough, E.O., Sheremeta, R.M., \& Shields, T.W. (2014). When parity promotes peace: Resolving conflict between asymmetric agents. Journal of Economic Behavior \& Organization, 99, 96-108.

Kollock, P. (1998). Social dilemmas: The anatomy of cooperation. Annual Review of Sociology, 24, 183-214.

Kolmar, M. (2013). Group conflicts: Where do we stand? Working Paper.

Kolmar, M., \& Rommeswinkel, H. (2013). Contests with group-specific public goods and complementarities in efforts. Journal of Economic Behavior \& Organization, 89, 9-22.

Konrad, K.A. (2009). Strategy and dynamics in contests. New York, NY: Oxford University Press.

Kugler, T., \& Bornstein, G. (2013). Social dilemmas between individuals and groups. Organizational Behavior and Human Decision Processes, 120, 191-205.

Kugler, T., Rapoport A. \& Pazy, A. (2010). Public good provision in inter-group conflicts: Effects of asymmetry and profit-sharing rule. Journal of Behavioral Decision Making, 23, 421-438.

Kurzban, R., \& DeScioli, P. (2008). Reciprocity in groups: information-seeking in a public goods game. European Journal of Social Psychology, 38, 139-158.

Ledyard, J. (1995). Public goods: A survey of experimental research. In J. Kagel and A.E. Roth (Eds.) Handbook of Experimental Economics, Princeton, NJ.

Lee, D. (2012). Weakest-link contest with group-specific public good prizes. European Journal of Political Economy, 28, 238-248.

Leibbrandt, A. \& Sääksvuori, L. (2012). Communication in intergroup conflicts. European Economic Review, 56, 1136-47.

Levine, D.K., \& Palfrey, T.R. (2007). The paradox of voter participation? A laboratory study. American Political Science Review, 101, 143-158.

Lim, W., Matros, A., \& Turocy, T.L. (2014). Bounded rationality and group size in Tullock contests: Experimental evidence. Journal of Economic Behavior \& Organization, 99, 155167.

Mago, S., Samek, A., \& Sheremeta, R.M. (2015). Facing your opponents: Social Identification and Information Feedback in Contests. Journal of Conflict Resolution, forthcoming.

Markussen, T., Reuben, E., \& Tyran, J. R. (2014). Competition, cooperation and collective choice. Economic Journal, 124, 163-195.

McCarter, M., Samek, A., \& Sheremeta, R.M. (2014). Divided loyalists or conditional cooperators? Creating consensus about cooperation in multiple simultaneous social dilemmas. Group and Organization Management, 39, 744-771. 
McCarter, M.W., \& Sheremeta, R.M. (2013). You can't put old wine in new bottles: The effect of newcomers on coordination in groups. PLoS One, 8, 1-9.

Millner, E.L. \& Pratt, M.D. (1989). An experimental investigation of efficient rent-seeking. Public Choice, 62, 139-151.

Morton, R.B. \& Williams, K.C. (2010). Experimental Political Science and the Study of Causality: From Nature to the Lab. New York, NY: Cambridge University Press.

Nalbantian, H.R. \& Schotter, A. (1997). Productivity under group incentives: An experimental study. American Economic Review, 87, 314-341.

Nitzan, S. (1991). Collective rent dissipation. Economic Journal, 101, 1522-1534.

Olson, M.J., (1965). The Logic of Collective Action. Cambridge, MA.: Harvard University Press.

Palfrey, T., \& Rosenthal, H. (1985). Voter participation and strategic uncertainty. American Political Science Review, 79, 62-78.

Potters, J.C., De Vries, C.G., \& Van Winden, F. (1998). An Experimental Examination of Rational Rent Seeking. European Journal of Political Economy, 14, 783-800.

Price, C.R., \& Sheremeta, R.M. (2011). Endowment effects in contests. Economics Letters, 111, 217-219.

Price, C.R., \& Sheremeta, R.M. (2015). Endowment origin, demographic effects and individual preferences in contests. Journal of Economics and Management Strategy, 2015, 24, 597-619.

Puurtinen, M., \& Mappes, T. (2009). Between-group competition and human cooperation. Proceedings of the Royal Society of London B: Biological Sciences, 276, 355-360.

Puurtinen, M., Heap, S., \& Mappes, T. (2015). The joint emergence of group competition and within-group cooperation. Evolution and Human Behavior, 36, 211-217.

Rabin, M. (1993). Incorporating fairness into game theory and economics. American Economic Review, 83, 1281-1302.

Rapoport, A., \& Bornstein, G. (1987). Intergroup competition for the provision of binary public goods. Psychological Review, 94, 291-299.

Rapoport, A., \& Bornstein, G. (1989). Solving public goods problems in competition between equal and unequal size groups. Journal of Conflict Resolution, 33, 460-479.

Reuben, E., \& Tyran, J. R. (2010). Everyone is a winner: Promoting cooperation through all-canwin intergroup competition. European Journal of Political Economy, 26, 25-35.

Rusch, H. (2014). The evolutionary interplay of intergroup conflict and altruism in humans: a review of parochial altruism theory and prospects for its extension. Proceedings of the Royal Society of London B, 281, 1-9.

Ryvkin, D. (2011). The optimal sorting of players in contests between groups. Games and Economic Behavior, 73, 564-572.

Sääksvuori, L., Mappes, T., \& Puurtinen, M. (2011). Costly punishment prevails in intergroup conflict. Proceedings of the Royal Society of London B, 278, 3428-3436.

Samek, A.S., \& Sheremeta, R.M. (2014). Recognizing contributors: An experiment on public goods. Experimental Economics, 17, 673-690.

Samek, A.S., \& Sheremeta, R.M. (2015). Selective recognition: How to recognize donors to increase charitable giving. Working Paper.

Sandler, T. (1993). The economic theory of alliances: A survey. Journal of Conflict Resolution, 37, 446-483.

Savikhin, A.C., \& Sheremeta, R.M. (2013). Simultaneous decision-making in competitive and cooperative games. Economic Inquiry, 51, 1311-1323. 
Sen, A. (2007). Identity and violence: The illusion of destiny. Penguin Books India.

Sheremeta, R.M. (2010). Experimental comparison of multi-stage and one-stage contests. Games and Economic Behavior, 68, 731-747.

Sheremeta, R.M. (2011). Perfect-substitutes, best-shot, and weakest-link contests between groups. Korean Economic Review, 27, 5-32.

Sheremeta, R.M. (2013). Overbidding and heterogeneous behavior in contest experiments. Journal of Economic Surveys, 27, 491-514.

Sheremeta, R.M. (2015). Behavioral dimensions of contests. In Congleton, R.D., Hillman, A.L., (Eds.), Companion to political economy of rent seeking, London: Edward Elgar, pp. 150-164.

Sheremeta, R.M. (2015). Impulsive behavior in competition: Testing theories of overbidding in rent-seeking contests. Working Paper.

Sheremeta, R.M., \& Zhang, J. (2010). Can groups solve the problem of over-bidding in contests? Social Choice and Welfare, 35, 175-197.

Sherif, M., Harvey, O.J., White, B.J., Hood, W.R., \& Sherif, C.W. (1961). Intergroup conflict and cooperation: The Robbers Cave experiment (Vol. 10). Norman, OK: University Book Exchange.

Sutter, M. (2006). Endogenous versus exogenous allocation of prizes in teams - Theory and experimental evidence. Labour Economics, 13, 519-549.

Sutter, M., \& Strassmair, C. (2009). Communication, cooperation and collusion in team tournaments - An experimental study. Games and Economic Behavior, 66, 506-525.

Tajfel, H. \& Turner, J. (1979). An Integrative Theory of Intergroup Conflict. In Stephen Worchel and William Austin, (Eds.), The Social Psychology of Intergroup Relations, Monterey, CA: Brooks/Cole.

Tan, J. H., \& Bolle, F. (2007). Team competition and the public goods game. Economics Letters, 96, 133-139.

Tingley, D.H., \& Walter, B.F. (2011). Can cheap talk deter? An experimental analysis. Journal of Conflict Resolution, 55(6), 996-1020.

Tullock, G. (1980). Efficient rent seeking. In James M. Buchanan, Robert D. Tollison, Gordon Tullock, (Eds.), Toward a theory of the rent-seeking society. College Station, TX: Texas A\&M University Press, pp. 97-112.

Van Dijk, F., Sonnemans, J. \& van Winden, F. (2001). Incentives systems in a real effort experiment. European Economic Review, 45, 187-214.

Wärneryd, K. (2001). Replicating contests. Economics Letters, 71, 323-327.

Wildschut, T., \& Insko, C.A. (2007). Explanations of interindividual-intergroup discontinuity: A review of the evidence. European Review of Social Psychology, 18, 175-211.

Wildschut, T., Pinter, B., Vevea, J.L., Insko, C.A., \& Schopler, J. (2003). Beyond the group mind: a quantitative review of the interindividual-intergroup discontinuity effect. Psychological Bulletin, 129, 698-722.

Yamagishi, T., \& Mifune, N. (2016). Parochial altruism: Does it explain modern human group psychology? Current Opinion in Psychology, 7, 39-43.

Zhang, J. (2012). Communication in asymmetric group competition over public goods. Working Paper. 